\title{
The 'New' Cultural Cleavage in Western Europe: A Coalescence of Religious and Secular Value Divides?
}

\author{
(Accepted manuscript)
}

\author{
Anna Pless, KU Leuven ${ }^{1}$ \\ Paul Tromp, KU Leuven \\ Dick Houtman, KU Leuven
}

\begin{abstract}
Moral traditionalism versus progressiveness and secular authoritarianism versus libertarianism are often understood as central to the same 'new' cultural cleavage in politics. Despite the often-found sizable correlations between these two cultural value divides, the present paper theorizes that this relationship is not a cross-contextual constant, but rather a specific feature of secularized contexts where moral traditionalism is relatively marginal. We test this theory by means of a two-stage statistical analysis of the data from the four waves of the EVS (1981-2008) for seventeen Western European countries. Our findings confirm that the two value divides are most strongly connected in the most secularized contexts because the latter are least morally traditionalist. While the two cultural divides hence tend to be distinct in more religious Western-European countries, they tend to coalesce into one single 'new' cultural divide in more secular ones.
\end{abstract}

Keywords: new cultural cleavage, value divides, authoritarianism, libertarianism, traditionalism, social progressiveness, cultural cleavage, cleavage politics

${ }^{1}$ Anna.kulkova@kuleuven.be, Centre for Sociological Research, Parkstraat 45 - box 3601, 3000 Leuven, Belgium. Tel: +32 16379868 


\section{Introduction}

Moral traditionalism and authoritarianism have often been found to be closely empirically interconnected and are in effect often understood as central to the same 'new' cultural cleavage in politics (Evans, Heath, and Lalljee 1996; Flanagan and Lee 2003). The moral traditionalism-progressiveness divide refers to the opposition between the religious and the secular about matters pertaining to sexuality, life and procreation, and the family, while the authoritarian-libertarian divide is an all-out secular one, which pits the low and highly educated against each other in their attitudes towards immigration and cultural diversity, law and order (Houtman 2003; Houtman, Achterberg, and Van der Waal 2011). Yet, given that moral traditionalists and authoritarians are two different and largely non-overlapping groups, as various observers have pointed out (De Koster and Van der Waal 2007; Lakatos 2015; Stenner 2005, 2009), then why have moral traditionalism and authoritarianism so often been found to be strongly positively related?

To solve this puzzle, this paper develops and tests the theory that the often found positive relationship between moral traditionalism and authoritarianism is not a crosscontextual constant, but an outcome of processes of secularization that spark ideals of personal liberty and hence a dual rejection of moral traditionalism and authoritarianism alike. This shows up in survey research as strong correlations between moral traditionalism and authoritarianism in secular contexts. The other way around, weak or even absent correlations between the two value divides are predicted for massively religious contexts, because there ideals of personal liberty are much less widespread.

The research question that we address in this paper is hence whether and why the link between moral traditionalism-progressiveness and secular authoritarianism-libertarianism is indeed stronger in more secularized contexts than in more religious ones. To answer this 
question, we study the link between the two value divides by means of survey data from the European Values Study 1981-2008 for seventeen Western-European countries that all have a Christian heritage and have not lived under Communist rule.

In the theoretical part of the paper (section 2), we first address the cultural cleavage and its evolution, to then theorize on how religious decline might have led to a coalescence of the religious and the secular value divides in Western Europe. We describe the data and the statistical methods in use in section 3, present our statistical findings in section 4 , and discuss our conclusions and their implications in the final section.

\section{Theory}

\subsection{One Cultural Cleavage and Two Cultural Value Divides?}

Cleavages represent structurally embedded social groups with contrasting interests and values that inform distinctive voting preferences (Bartolini and Mair 1990; Lipset and Rokkan 1967). Among the cleavages outlined by Lipset and Rokkan in their book Party Systems and Voter Alignments: Cross-national Perspectives (1967), the class cleavage captured most attention of researchers in the subsequent decades. It refers to the class-based opposition between Left and Right parties, representing opposite stances on the ideal relationships between state and market (Dalton 1996; Lijphart 1982).

However, class interests were not the only factor that influenced voting behavior and party systems, as Lipset and Rokkan also acknowledged various other cleavages, like the one based on religion (Lipset and Rokkan 1967). Across Western Europe, this religious cleavage either overlapped with other societal divides like in Norway (Ertman 2009) or constituted an independent dimension of political competition, e.g., via parties of religious defense in 
countries like Belgium and the Netherlands (Kalyvas 1996). It reflected the conflict between church and state, or, at the individual level, between religious and secular individuals, with the religious more likely to vote for Christian-Democratic (or other distinctively culturally conservative) parties (Knutsen 2010). At the heart of this cleavage lies a value divide about the societal role of religion, i.e., the degree to which religious norms should be reflected in state laws and followed by citizens.

Although Western party systems in the beginning of the 1960s still reflected the 'frozen' social cleavages of the 1920s (Lipset and Rokkan 1967), the next decades were marked by far-reaching changes. In particular, the so-called 'counter culture' of the 1960s and 1970s brought cultural issues pertaining to individual liberty to the political agendas of Western European countries (Campbell 2007; Houtman, Aupers, and De Koster 2011; Marwick 1998). These changes sparked academic debates about the evolution of cleavagebased politics, with special attention to the emergence of a so-called 'new cultural cleavage' that has allegedly only gained in social and political salience since (Inglehart 1977; Kriesi 1998, 2010).

These debates have produced various characterizations of the cultural value divide held to be central to the 'new' cultural cleavage, e.g., 'libertarian/authoritarian' (Flanagan and Lee 2003; Kitschelt and McGann 1997; Stubager 2008), 'post-materialist/materialist' (Inglehart 1977), 'self-expression/survival' (Inglehart and Baker 2000; Inglehart and Welzel 2005), 'green-alternative-libertarian/traditional-authoritarian-nationalist' (Hooghe, Marks, and Wilson 2002), and ‘libertarian-universalistic/traditionalist-communitarian' (Bornschier 2010). Central to these various definitions of the cultural divide is the idea that cultural issues pertain to problems of social order and represent models for dealing with those problems. At least two of such models, one religious and one secular, are seen as underlying the value 
conflicts at the heart of the cultural cleavage (see for instance Norris and Inglehart 2019). The religious model gives rise to conflicts between moral traditionalism and moral progressiveness, while the secular model gives rise to conflicts between authoritarianism and libertarianism.

The secular model of social order pits the authoritarian low educated and the libertarian highly educated against each other in their attitudes towards immigration and cultural diversity, law and order (De Koster and Van der Waal 2007; Houtman 2003; Houtman, Achterberg and Van der Waal 2011). These issues pertain to cultural hierarchies and to (un)willingness to accept cultural diversity, not least the cultural diversity brought by immigrants in recent decades (De Koster and Van der Waal 2007; Stenner 2005). The less educated are more likely to value sameness and conformity over diversity, and thus embrace authoritarian stances towards immigration, ethnic diversity, and law and order. The more educated, on the other hand, are more inclined to be libertarian and to embrace diversity and individualism (Houtman 2003; Stubager 2008, 2010; Van de Werfhorst and De Graaf 2004).

The religious model of social order sparks conflicts between the religious and the secular about the legitimacy of traditional Christian doctrines (for the case of Western Europe) and behavioral norms (Finke and Adamczyk 2008; Storm 2016). The latter pertain especially to matters of sexuality, life and procreation, family issues and gender roles. Religious individuals understand Christian norms and guidelines on how to live properly as pre-given by a higher divine authority, as having proven their efficacy over centuries, and as distinct from and superior to conventional and man-induced secular laws (McCullough and Willoughby 2009). Non-religious moral progressivists, on the other hand, do not ground their moral principles in religion and reject the latter's claims of unquestionable authority and 
predefined social roles to be followed literally (Brown 2009; Houtman, Aupers, and De Koster 2011).

These two cultural value divides, i.e., moral traditionalism-progressiveness and authoritarianism-libertarianism, have often been understood as together forming the heart of the 'new' cultural cleavage. All things considered though, this is somewhat odd. In the first place, the moral traditionalism-progressiveness value divide is of course not 'new' at all. It has in fact always been central to the religious cleavage as already discussed by Lipset and Rokkan (1967) in the 1960s, well before the emergence of the 'new' cultural cleavage. Moreover, with the rise of the 'new' cultural cleavage secular issues pertaining to immigration and cultural diversity, law and order have become increasingly important (Kriesi 2010), while religion and traditional morality simultaneously have lost much of their former significance in Western Europe. Yet, the two cultural value divides have often been found to be empirically interconnected (e.g., Evans, Heath, and Lalljee 1996; Flanagan and Lee 2003) and have therefore been widely combined into one single scale to represent the 'new' cultural dimension in politics (Achterberg and Houtman 2006; Munzert and Bauer 2013; Norris and Inglehart 2019).

Various studies have meanwhile nonetheless pointed out that moral traditionalists and authoritarians are by and large different, non-overlapping groups, suggesting the need to disentangle rather than combine the two value divides (Lakatos 2015; Stenner 2005, 2009). Indeed, research by De Koster and Van der Waal (2007) suggests that the often-found positive relationship between the two scales is due to moral progressivists rejecting both moral traditionalism and authoritarianism in the name of personal liberty. They conclude from this that moral traditionalism and secular authoritarianism are different value divides that need to be kept apart and treated separately rather than being combined into one single 
'new' cultural divide, as so many have done. This conclusion assumes that the relationship between the two value divides is identical across contexts, but the fact that their data come from the Netherlands, one of the most secularized and morally progressive countries in the world (see Norris and Inglehart 2004), may suggest otherwise. We therefore theorize in what follows that it is precisely secularization that has sparked a rejection of both moral traditionalism and authoritarianism in the name of personal liberty. The outcome of it is strong correlations between the two in largely secular and morally progressive contexts and weak or even absent ones in massively religious and morally traditional ones.

\subsection{Secularization and Value Divides: Hypotheses}

The 1960s witnessed massive and rapid processes of secularization, driven by critiques of religion and the churches as standing in the way of personal liberty, not least in matters of sexuality, life and procreation, family and gender roles (Brown 2009; McLeod 2007). The result was a decline of religion's social significance and a shift from the dominance of religiously informed moral traditionalism to a growing importance of individual liberty and personal authenticity. The so-called 'counter culture' back then did however not merely critique religion and moral traditionalism, but was critical of authority generally, irrespective of whether the latter was religiously or secularly based (Roszak 1972; Zijderveld 1970). The counter culture as such exemplifies how secularization stimulates a rejection in the name of personal liberty of moral traditionalism and secular authoritarianism alike. Secularization, and more specifically the turn to moral progressiveness that comes with it, thus appears to have strengthened the relationship between the value divides of religiouslyinformed moral traditionalism-progressiveness and secular authoritarianism-libertarianism.

The turmoil of the 1960s and 1970s has meanwhile left its lasting imprint on Western European societies (Houtman, Aupers, and De Koster 2011; Marwick 1998), not least in the 
realm of politics (Dalton 1996; Elff 2007; Inglehart 1977). Still today, the heirs of the counter culture, i.e., the New-Leftist parties and their secular voters and sympathizers, are critical about traditional religious as well as secular rightist-authoritarian tendencies (e.g., Dolezal 2010; Kriesi 2010; Stubager 2010). The latter tendencies have become much stronger due to an increased salience of issues of immigration and cultural diversity, law and order from the 1980s onwards (Bornschier 2010). Especially immigration issues have since then conquered Western-European political agendas, with the most economically developed and culturally progressive Northern countries having become most visibly divided over these issues (Dennison and Geddes 2019; Van Oorschot 2006; Silva 2018; Stubager 2010). This period since the 1980s has witnessed the emergence and electoral success of New-Rightist political parties that politicized these issues, not least by framing immigration as posing a threat to national identity and cultural sameness (Betz and Johnson 2004; Dolezal 2010; Ignazi 2003; Kriesi 2010; Kriesi et al. 2008).

This rightist-authoritarian backlash since the 1980s has in the process underscored how the 1960s have dealt more of a blow to religious moral traditionalism than to secular authoritarianism. While in the 1970s, advocates of personal liberty still primarily faced religious and morally traditionalist adversaries, from the 1980s onwards their enemies increasingly tended to have exclusively secular authoritarian profiles. Since the 1960s, then, religion and moral traditionalism have not only massively declined but have in the process also lost much of their former political salience, giving way to a redefinition of problems of social order in a secular direction (Achterberg et al. 2009; Akkerman 2005). Yet, it is clear that religion and moral traditionalism have not disappeared in even the most secularized Western-European countries (Halman and Draulans 2006) and it would be similarly wrong to assert that the authoritarianism-libertarianism divide did not exist before the 1980s (see for instance Lipset (1959) on working-class authoritarianism). 
While the two cultural value divides have hence always co-existed, processes of secularization appear to have sparked a quest for personal liberty that has led rejections of moral traditionalism and of authoritarianism to increasingly coincide, producing stronger correlations between scales measuring the two. While this makes it understandable why so many scholars of contemporary politics have treated the two value divides as together constituting one new value cleavage (Achterberg 2006; Evans, Heath, and Lalljee 1996; Flanagan and Lee 2003; Houtman 2001; De Witte and Billiet 1999), it is then in fact not so much moral traditionalism and authoritarianism that have come to coincide, but rather their rejections by those foregrounding values of personal liberty. If this is indeed what has happened, the strength of the relationship between the two cultural value divides should be stronger in contexts where religion is less prevalent, because processes of secularization there resulted in a sizeable group of population who reject both traditionalism and authoritarianism.

If this theory about value change holds any water, it should be possible to confirm four hypotheses that can be derived from it. The first one predicts that the relationship between moral traditionalism-progressiveness and authoritarianism-libertarianism has grown stronger in time $(\mathrm{H} 1)$. The three remaining ones address the explanation of this process. The second and third hypotheses predict that the link between the two value divides is stronger in more secularized contexts than in more religious ones $(\mathrm{H} 2)$, because the latter are more morally progressive and less morally traditionalist (H3). This means that we expect lower levels of contextual religiosity to strengthen the relationship between the two value divides due to lower levels of contextual moral traditionalism. Finally, our fourth and final hypothesis predicts that the strengthening of the relationship between the two value divides across time (see $\mathrm{H} 1$ ) is caused by processes associated with secularization (see $\mathrm{H} 2$ and $\mathrm{H} 3$ ) and the effect of time is explained away by it (H4). 


\section{Data and Methods}

\subsection{Data}

We aim to study whether the link between authoritarianism and traditionalism has become stronger in time, due to a process of secularization that has increased moral progressiveness. To do so, we analyze the data of the European Values Study for seventeen Western-European countries, that all have a Christian heritage and not lived under Communist rule (EVS 2011). We use all four available waves of the study (1981, 1990, 1999, and 2008). The resulting dataset includes more than 69,000 individuals nested within 64 contexts, four waves and seventeen countries. Those countries include Austria (only 3 waves), Belgium, Denmark, Finland (only 3 waves), France, Germany, Iceland, Ireland, Italy, Malta, Netherlands, Norway (only 3 waves), Portugal (only 3 waves), Spain, Sweden, United Kingdom, and Northern Ireland. ${ }^{i}$ All descriptive statistics are available in the appendix.

\subsection{Method}

The EVS data in use are hierarchical in their nature as respondents are nested within contexts (country-years) that are nested within waves and within countries. In most cases, researchers analyze this kind of data with multilevel modeling that allows to simultaneously estimate equations for the individual and contextual levels, as well as cross-level interactions. Fitting multilevel models can, however, cause computational problems if within-country samples are large, observations are nested within several levels simultaneously, and more than one cross-level interaction needs to be estimated (Gebel and Giesecke 2011) - all conditions that apply to this study. Following Fairbrother (2014) and Franzese (2005) we, therefore, opt for an alternative strategy, i.e., a two-stage multilevel analysis. We thus treat country-year combinations as unique contexts and estimate equations for the individual and 
contextual levels separately. This allows all individual-level effects to vary across countries and time without imposing any further distributional assumptions (Gebel and Giesecke 2011).

In the first stage, for each country-year combination, we compute the zero-order correlation between the two value divides as a measure of connectedness. In the second stage, these correlation scores are used as a dependent variable in regression analysis to test whether the strength of the link is indeed getting stronger in 1) time, and in 2) more secularized societies, because 3) they are the least traditionalist. We thus treat country-years as observation units instead of individuals and perform multilevel modeling with countries as a second-level grouping variable. This two-stage approach solves a rather common problem of obtaining statistically significant results with negligible effect-sizes that usually occurs due to too large samples on the individual level.

\subsection{Measurement}

In order to compute our dependent variable - a measure of connectedness between the moral traditionalism-progressiveness and secular authoritarianism-libertarianism value divides within each context - we first require individual scores for both divides and justify their use as separate value scales. The moral traditionalism-progressiveness scale measures respondent's moral stances on matters of life and death, procreation and family life, and is based on five questions indicating whether a respondent finds homosexuality, abortion, euthanasia, divorce, and suicide justifiable. ${ }^{\text {ii }}$ For those who responded validly to at least 4 of these 5 questions, scale scores were assigned as mean standardized scores and then transformed to range from 0 to 10 , with 10 indicating strongest moral traditionalism. The scale is highly reliable with an overall Cronbach's Alpha of 0.82 .iii

The measurement of authoritarianism-libertarianism posed more difficulties due to a scarcity of suitable items, but eventually we chose for the best available option by selecting 
5 questions; 4 about opposition to having 1) immigrants, 2) people of different race, 3) Muslims, and 4) ex-criminals as neighbors and 5) one about whether they think the native born should have priority in getting a job. ${ }^{\text {iv }}$ Because the questions about opposition to Muslims as neighbors and about privileging the native born on the labor market were not asked in the first wave, scale scores were assigned as mean standardized scores to all those who responded validly to at least three of these five questions. The scores were then transformed to range from 0 to 10 , with 10 indicating strongest authoritarianism. The resulting scale is fairly reliable with an overall Cronbach's Alpha of $0.67 .^{v}$

Factor analysis with Oblimin rotation demonstrates that all authoritarianism items load on the first factor and all traditionalism items on the second. The two factors have Eigenvalues of respectively 3.53 and 1.96 (before rotation), explain $90 \%$ of the variance together, and have a correlation of 0.24 (see table 1$)$.

(Insert Table 1 about here)

As indicated above, the correlation between moral traditionalism and authoritarianism is then computed for each of the country-year combinations separately to obtain the dependent variable to be used in this study. For all contexts combined the correlation is quite low reaching 0.22, the highest one being 0.29 for the Netherlands in 1990 and the lowest ones being statistically indistinguishable from zero (Northern Ireland in 1981 and Portugal in 1999). The intraclass correlation score of 0.34 suggests that multilevel modeling is required to account for country-level variation in the dependent variable.

The explanatory variables are 1) time, 2) contextual religiosity, and 3) contextual moral traditionalism. Time is measured as the wave of the EVS $(1981-1990-1999-$ 2008), and is introduced in the models as a continuous predictor. Contextual religiosity is computed for each of the country-year combinations as the mean score of an individual-level 
scale that consists of attending religious services at least once a month and believing in god, heaven, hell, sin, and life after death. ${ }^{\mathrm{vi}}$ Although all these variables are binary, they are highly correlated and load heavily on one factor with an Eigenvalue of 3.21 that explains $89 \%$ of the variance. The resulting scale (mean standardized scores) is highly reliable with Cronbach's alpha of 0.86 and is recoded to range from 0 to 10 (most religious). The least religious context is Sweden in 2008 (2.33) and the most religious one is Malta in 1981 (9.28).

Contextual moral traditionalism is computed for each of the country-year combinations as the mean score of the individual-level scale for moral traditionalism. The least and most morally traditional contexts are respectively Sweden in 2008 (3.27) and Malta in 1981 (9.61). Contextual authoritarianism is computed in a similar fashion and used as a control variable in the statistical analyses. It ranges from 1.32 in Sweden in 1999 to 4.01 in Malta in 2008.

\section{Empirical Analysis}

The strength of the link between the two value divides varies substantially across country-year contexts. The correlations range from statistically indistinguishable from zero in Portugal in 1999 and Northern Ireland in 1981 to 0.28 in Iceland in 1999 and 0.29 in the Netherlands in 1990. Figure 1 plots the zero-order correlations against contextual religiosity for all country-year contexts under study, showing that the link between the two value divides is indeed stronger in the more secularized societies and weaker in the more religious ones.

\section{(Insert Figure 1 about here)}

To test our hypotheses, we perform multilevel regression analysis with the traditionalism-authoritarianism correlation for each country-year combination as the dependent variable, introducing the explanatory variables step by step. Model 1 in Table 2 
provides support for our first hypothesis: the two value divides have indeed become more connected in the more recent years. The correlation between traditionalism and authoritarianism across all contexts in 1981 is estimated to average about 0.14 (=constant + effect of time), while it reaches an average of 0.18 in 2008 - a change that is exclusively accounted for by time, as the control variable contextual authoritarianism turns out to have an insignificant effect.

Model 2 then adds contextual religiosity to the equation. This reveals that, consistent with our second hypothesis, the link between the value divides is indeed stronger in more secularized societies as compared to more religious ones, even though the coefficient is only significant at the $10 \%$ significance level. Model 2 moreover shows that the effect of time (the link getting stronger in time) is mediated by this effect of secularization: adding contextual religiosity to the model leads to a decline in statistical significance of the time-variable.

\section{(Insert Table 2 about here)}

Our third hypothesis suggests that the link between the two divides is stronger in more secularized contexts because the latter are less morally traditionalist. Model 3 supports this hypothesis: the correlation between the two value divides is indeed stronger in more morally progressive contexts and weaker in more traditionalist ones and this explains away the previously recorded difference between more and less religious contexts. On average, a onepoint increase in contextual traditionalism corresponds to a decline in the correlation between traditionalism and authoritarianism of about 0.046 . With the other variables in the model held constant, the difference in the traditionalism-authoritarianism correlation between the most and the least traditionalist contexts is around 0.3 , which is quite large. The explanatory power of the model is also significantly improved by adding contextual traditionalism to the equation. While Model 1 and Model 2, both without contextual moral traditionalism, explain 
only about $9-10 \%$ of the variance, this rises to $25 \%$ with contextual moral traditionalism being added in Model 3 (see Bryk/Raudenbush $\mathrm{R}^{2}$ ).

Finally, the dynamics of secularization-induced increases in contextual moral progressiveness does indeed prove to be responsible for the strengthening of the link between the value divides across time as recorded in Model 1. For Model 3 demonstrates that the effect of contextual traditionalism is not only stronger than those of both time and contextual religiosity, but moreover reduces their effects to non-significance and hence explains them away. This means that contextual traditionalism is responsible for the previously recorded effects of time and contextual religiosity. This also confirms our fourth hypothesis: the overlap between the two value divides has become stronger in time due to the increase in moral progressiveness that has come with secularization. In other words, and on a more theoretical note: to the extent that moral traditionalism-progressiveness and authoritarianismlibertarianism coalesce and constitute the cultural heart of a 'new' cultural cleavage together, this appears to be an outcome of secularization.

\section{Conclusion and Discussion}

In this paper, we have studied whether the link between the moral traditionalismprogressiveness and the secular authoritarianism-libertarianism value divides in Western Europe is a consequence of secularization and the corresponding decline in moral traditionalism rather than a universal phenomenon. Our findings do indeed suggest that this is the case, i.e., that the two value divides are more strongly connected in secularized contexts because the latter's moral progressiveness informs a dual opposition to moral traditionalism and secular authoritarianism alike. Alternatively, in more religious and traditionalist contexts, where non-religious moral progressiveness is not that widespread, the link between the two 
divides tends to be either extremely weak or even completely absent. While the two cultural divides hence tend to be distinct in more religious Western-European countries, they tend to coalesce into one single 'new' cultural divide in more secular ones.

While our findings thus highlight the need to differentiate between the two cultural value divides in massively religious contexts, it simultaneously calls for a careful distinction between the two in more secularized contexts. Perhaps most important, our findings suggest that studies exclusively aimed at examining either secular authoritarianism or moral traditionalism in massively secularized settings need to carefully control for the other value divide to prevent misinterpretations of research findings.

The major contribution of our paper to the wider field of cleavage politics is that it suggests a new theory on the emergence of the 'new' cultural cleavage. Studies traditionally assume that the latter emerged in the second half of the twentieth century as a result of the decline of the class cleavage and the decline in the salience of the class-based distributive issues central to it. The arguably most influential account of the process attributes the increasing salience of cultural issues to economic development and the increased fulfillment of basic needs of the Western population (Inglehart 1977). Recent studies provide evidence, however, that the class cleavage may not have declined at all, but has rather increasingly come to be outshined and made invisible by the newly emerged cultural cleavage (Gingrich and Häusermann 2015; Van der Waal, Achterberg, and Houtman 2007). This, of course, then raises the question of how and why the new cultural cleavage has emerged in the first place, and our findings point in the unexpected direction of processes of secularization.

Even though the low, or even absent, correlations between moral traditionalism and authoritarianism in the most religious contexts confirm our theory, readers may be surprised that even the most secular contexts do not produce correlations higher than 0.29 . This may be 
because the scale for secular authoritarianism that we have used is far from perfect, mainly relying on unwelcoming attitudes vis-a-vis 'deviant' neighbors. Ideally, we would prefer to have more questions on authoritarianism to choose from, even if only in upcoming waves of comparative survey projects, especially so because of the increasing presence of the NewRightist parties on the European political arenas. Currently existing datasets seem to have either questions on moral traditionalism or questions on authoritarianism, but never both of them, which may indeed be another explanation of why the two value divides are so often taken to be virtually identical and interchangeable.

Needless to say, more detailed research into the economic and religious roots of the new cultural cleavage is called for to further substantiate this alternative theory about its emergence. Another logical next step would be to study changes in how the two value divides drive voting behavior, carefully controlling for each other's electoral influence, as suggested above. Doing so, special attention needs to be paid to the prevalence of pronounced religious cultural voting in massively religious countries (i.e., voting for either religious or secular parties) and secular cultural voting in more secular ones (especially for either New-Leftist or New-Rightist parties).

\section{Literature}

Achterberg, Peter. 2006. 'Class Voting in the New Political Culture: Economic, Cultural and Environmental Voting in 20 Western Countries'. International Sociology 21(2): 237-61.

- 2009. 'A Christian Cancellation of the Secularist Truce? Waning Christian Religiosity and Waxing Religious Deprivatization in the West'. Journal for the Scientific Study of Religion 48(4): 687-701.

Achterberg, Peter, and Dick Houtman. 2006. 'Why Do so Many People Vote "Unnaturally"? A Cultural Explanation for Voting Behaviour'. European Journal of Political Research 
45(1): 75-92.

Akkerman, Tjitske. 2005. 'Anti-Immigration Parties and the Defence of Liberal Values: The Exceptional Case of the List Pim Fortuyn'. Journal of Political Ideologies 10(3): 337-54.

Bartolini, Stefano, and Peter Mair. 1990. Identity, Competition and Electoral Availability: The Stabilisation of European Electorates 1885-1985. New York: Cambridge University Press.

Betz, Hans-Georg, and Carol Johnson. 2004. 'Against the Current — Stemming the Tide: The Nostalgic Ideology of the Contemporary Radical Populist Right'. Journal of Political Ideologies 9(3): 311-27.

Bornschier, Simon. 2010. 'The New Cultural Divide and the Two-Dimensional Political Space in Western Europe'. West European Politics 33(3): 419-44.

Brown, Callum G. 2009. The Death of Christian Britain: Understanding Secularisation, 18002000. London: Routledge.

Campbell, Colin. 2007. The Easternization of the West: A Thematic Account of Cultural Change in the Modern Era. Boulder: Paradigm.

Dalton, Russell J. 1996. 'Political Cleavages, Issues, and Electoral Change'. In Comparing Democracies: Elections and Voting in Global Perspective, ed. Lawrence LeDuc. Thousand Oaks (Calif.): Sage, 319-42.

Dennison, James, and Andrew Geddes. 2019. 'A Rising Tide? The Salience of Immigration and the Rise of Anti-Immigration Political Parties in Western Europe'. The Political Quarterly 90(1): 107-16.

Dolezal, Martin. 2010. 'Exploring the Stabilization of a Political Force: The Social and Attitudinal Basis of Green Parties in the Age of Globalization'. West European Politics 33(3): 534-52.

Elff, Martin. 2007. 'Social Structure and Electoral Behavior in Comparative Perspective: The Decline of Social Cleavages in Western Europe Revisited'. Perspectives on Politics 5(2): 277-94.

Ertman, Thomas. 2009. 'Western European Party Systems and the Religious Cleavage'. In Religion, Class Coalitions, and Welfare States, eds. Kees Van Kersbergen and Philip 
Manow. Cambridge: Cambridge University Press, 39-55.

Evans, Geoffrey, Anthony Heath, and Mansur Lalljee. 1996. 'Measuring Left-Right and Libertarian-Authoritarian Values in the British Electorate'. British Journal of Sociology: 93-112.

EVS. 2011. European Values Study 1981-2008, Longitudinal Data File. Cologne, Germany: GESIS Data Archive.

Fairbrother, Malcolm. 2014. 'Two Multilevel Modeling Techniques for Analyzing Comparative Longitudinal Survey Datasets'. Political Science Research and Methods 2(1): 119-40.

Finke, Roger, and Amy Adamczyk. 2008. 'Cross-National Moral Beliefs: The Influence of National Religious Context'. The Sociological Quarterly 49(4): 617-52.

Flanagan, Scott C, and Aie-Rie Lee. 2003. 'The New Politics, Culture Wars, and the Authoritarian-Libertarian Value Change in Advanced Industrial Bemocracies'. Comparative Political Studies 36(3): 235-70.

Franzese, Robert J. 2005. 'Empirical Strategies for Various Manifestations of Multilevel Data'. Political Analysis 13(4): 430-46.

Gebel, Michael, and Johannes Giesecke. 2011. 'Labor Market Flexibility and Inequality: The Changing Skill-Based Temporary Employment and Unemployment Risks in Europe'. Social Forces 90(1): 17-39.

Gingrich, Jane, and Silja Häusermann. 2015. 'The Decline of the Working-Class Vote, the Reconfiguration of the Welfare Support Coalition and Consequences for the Welfare State'. Journal of European Social Policy 25(1): 50-75.

Halman, Loek, and Veerle Draulans. 2006. 'How Secular Is Europe?' British Journal of Sociology 57(2): 263-88.

Hooghe, Liesbet, Gary Marks, and Carole J Wilson. 2002. 'Does Left/Right Structure Party Positions on European Integration?' Comparative Political Studies 35(8): 965-89.

Houtman, Dick. 2001. 'Class, Culture, and Conservatism: Reassessing Education as a Variable in Political Sociology'. In The Breakdown of Class Politics: A Debate on Post-Industrial Stratification, Washington, DC: Woodrow Wilson Center Press, 161-96. 
2003. Class and Politics in Contemporary Social Science: 'Marxism Lite' and Its Blind Spot for Culture. New York: Routledge.

Houtman, Dick, Peter Achterberg, and Jeroen Van der Waal. 2011. 'One Nation Without God? Post-Christian Cultural Conflict in the Netherlands'. In Paradoxes of Individualization: Social Control and Social Conflict in Contemporary Modernity, Aldershot, 123-40.

Houtman, Dick, Stef Aupers, and Willem De Koster. 2011. 'Introduction: The Myth of Individualization and the Dream of Individualism'. In Paradoxes of Individualization: Social Control and Social Conflict in Contemporary Modernity, Aldershot, 1-24.

Ignazi, Piero. 2003. Extreme Right Parties in Western Europe. New York: Oxford University Press.

Inglehart, Ronald. 1977. The Silent Revolution: Changing Values and Political Styles among Western Publics. Princeton: Princeton University Press.

Inglehart, Ronald, and Wayne E Baker. 2000. 'Modernization, Cultural Change, and the Persistence of Traditional Values'. American Sociological Review 65(1): 19-51.

Inglehart, Ronald, and Christian Welzel. 2005. Modernization, Cultural Change and Democracy: The Human Development Sequence. Cambridge: Cambridge University Press.

Kalyvas, Stathis N. 1996. The Rise of Christian Democracy in Europe. Ithaca (N.Y.): Cornell University Press.

Kitschelt, Herbert, and Anthony J McGann. 1997. The Radical Right in Western Europe: A Comparative Analysis. Ann Arbor: University of Michigan Press.

Knutsen, Oddbjørn. 2010. 'The Religious Cleavage in 24 European Countries - A Comparative Study’. In Comparative Democratic Politics Seminar, University of Oslo, 1-20.

De Koster, Willem, and Jeroen Van der Waal. 2007. 'Cultural Value Orientations and Christian Religiosity: On Moral Traditionalism, Authoritarianism, and Their Implications for Voting Behavior'. International Political Science Review 28(4): 451-67.

Kriesi, Hanspeter. 1998. 'The Transformation of Cleavage Politics: The 1997 Stein Rokkan Lecture'. European Journal of Political Research 33(2): 165-85.

- 2008. West European Politics in the Age of Globalization. Cambridge: Cambridge 
University Press.

. 2010. 'Restructuration of Partisan Politics and the Emergence of a New Cleavage Based on Values'. West European Politics 33(3): 673-85.

Lakatos, Zoltán. 2015. 'Traditional Values and the Inglehart Constructs'. Public Opinion Quarterly 79(S1): 291-324.

Lijphart, Arend. 1982. 'The Relative Salience of the Socio-Economic and Religious Issue Dimensions: Coalition Formations in Ten Western Democracies, 1919-1979'. European Journal of Political Research 10(3): 201-11.

Lipset, Seymour Martin. 1959. 'Democracy and Working-Class Authoritarianism'. American Sociological Review 24(4): 482-501.

Lipset, Seymour Martin, and Stein Rokkan. 1967. 'Cleavage Structures, Party Systems, and Voter Alignments: An Introduction'. In Party Systems and Voter Alignments: CrossNational Perspectives, eds. Seymour Martin Lipset and Stein Rokkan. New York: Free Press.

Marwick, Arthur. 1998. The Sixties: Cultural Revolution in Britain, France, Italy, and the United States, 1958-1974. Oxford: Oxford University Press.

McCullough, Michael, and Brian Willoughby. 2009. 'Religion, Self-Regulation, and SelfControl: Associations, Explanations, and Implications'. Psychological Bulletin 135(1): 69-93.

McLeod, Hugh. 2007. The Religious Crisis of the 1960s. New York: Oxford University Press. Munzert, Simon, and Paul Bauer. 2013. 'Political Depolarization in German Public Opinion, 1980-2010'. Political Science Research and Methods 1(1): 67-89.

Norris, Pippa, and Ronald Inglehart. 2004. Sacred and Secular: Religion and Politics Worldwide. Cambridge: Cambridge University Press.

- 2019. Cultural Backlash: Trump, Brexit, and the Rise of Authoritarian Populism. Cambridge, United Kingdom: Cambridge University Press.

Van Oorschot, Wim. 2006. 'Making the Difference in Social Europe: Deservingness Perceptions among Citizens of European Welfare States'. Journal of European Social Policy 16(1): 23-42. 
Roszak, Theodore. 1972. The Making of a Counter Culture: Reflection on the Technocratic Society and Its Youthful Opposition. London: Faber \& Faber.

Silva, Bruno Castanho. 2018. 'Populist Radical Right Parties and Mass Polarization in the Netherlands'. European Political Science Review 10(2): 219-44.

Stenner, Karen. 2005. The Authoritarian Dynamic. Cambridge: Cambridge University Press.

_. 2009. 'Three Kinds of “Conservatism”, Psychological Inquiry 20(2-3): 142-59.

Storm, Ingrid. 2016. 'Morality in Context: A Multilevel Analysis of the Relationship between Religion and Values in Europe'. Politics and Religion 9(1): 111-38.

Stubager, Rune. 2008. 'Education Effects on Authoritarian-Libertarian Values: A Question of Socialization'. British Journal of Sociology 59(2): 327-50.

— 2010. 'The Development of the Education Cleavage: Denmark as a Critical Case'. West European Politics 33(3): 505-33.

Van der Waal, Jeroen, Peter Achterberg, and Dick Houtman. 2007. 'Class Is Not Dead - It Has Been Buried Alive: Class Voting and Cultural Voting in Postwar Western Societies (1956-1990)'. Politics \& Society 35(3): 403-26.

Van de Werfhorst, Herman, and Nan Dirk De Graaf. 2004. 'The Sources of Political Orientations in Post-Industrial Society: Social Class and Education Revisited'. British Journal of Sociology 55(2): 211-35.

De Witte, Hans, and Jaak Billiet. 1999. 'Economic and Cultural Conservatism in Flanders: In Search of Concepts, Determinants and Impact on Voting Behavior'. In Ideology in the Low Countries. Trends, Models and Lacunae, Assen: Van Gorcum, 91-120.

Zijderveld, Anton C. 1970. The Abstract Society: A Cultural Analysis of Our Time. Garden City (N.Y.): Doubleday. 


\section{Tables and Figures}

Table 1. Moral traditionalism and secular authoritarianism items: factor analysis results

\begin{tabular}{llll}
\hline Variable & Factor 1 & Factor 2 & Uniqueness \\
\hline Moral Traditionalism - Progressiveness & & & \\
Homosexuality & & 0.66 & 0.50 \\
Abortion & & 0.79 & 0.36 \\
Suicide & & 0.55 & 0.69 \\
Divorce & & 0.78 & 0.38 \\
Euthanasia & & & 0.55 \\
\hline Secular Authoritarianism-Libertarianism & 0.91 & & 0.17 \\
Immigrants & 0.88 & & 0.21 \\
Race & 0.86 & & 0.26 \\
Muslims & 0.44 & & 0.77 \\
Ex-criminals & 0.41 & & 0.75 \\
Jobs scarcity vs migrants & 2 & \\
\hline N of factors & 0.90 & \\
Explained variance (2 factors) & 0.24 & \\
Correlation between factors & 48,662 & \\
Total N (individuals) & & \\
\hline Blans represent & & \\
\hline
\end{tabular}

Blanks represent loadings $<0.3$; Factor analysis (IPF) based on polychoric correlation matrix with Oblimin rotation; all items are standardized. 
Figure 1. The Link between the Two Value Divides in Religious versus Secular Contexts (zero-order correlations by country-year)

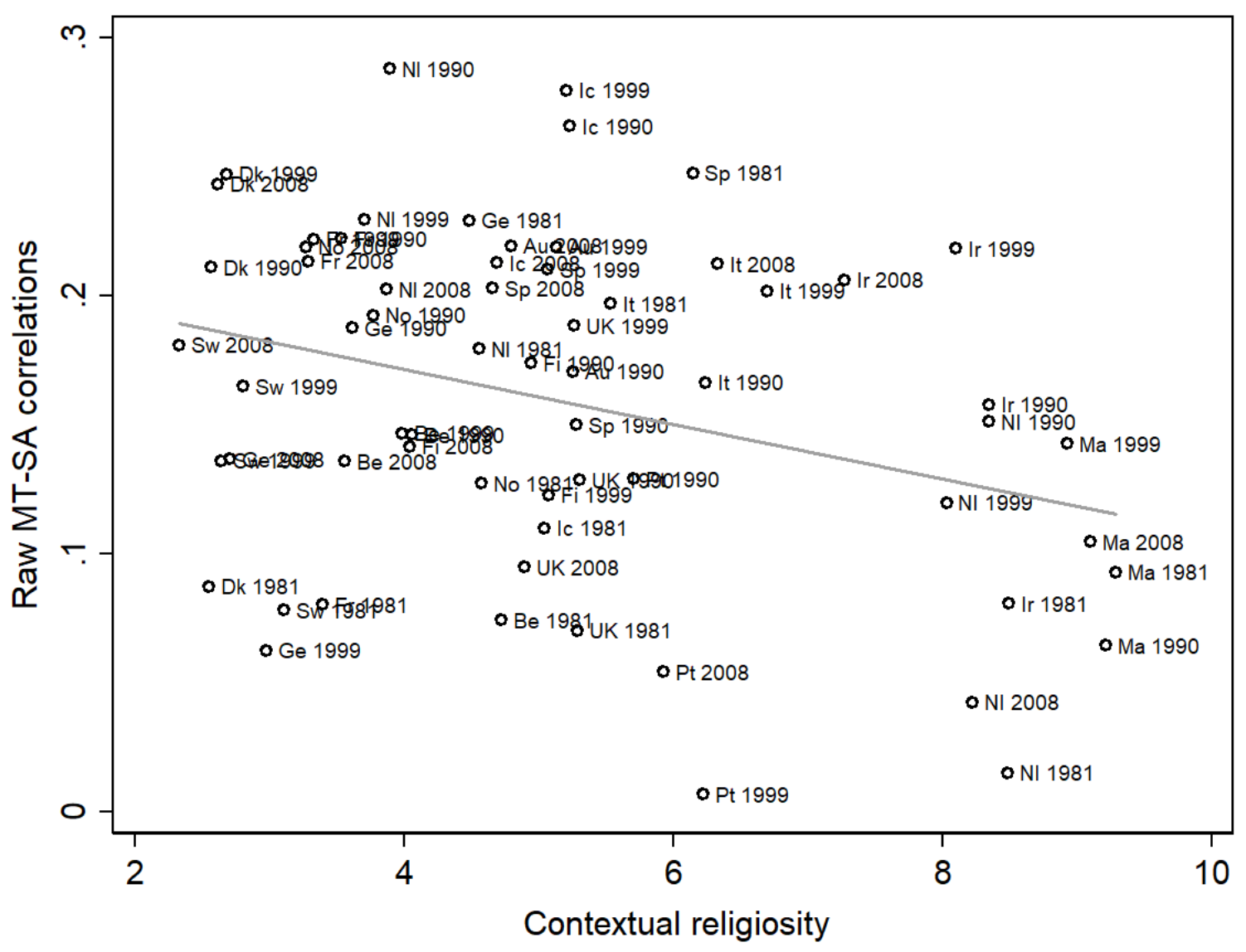


Table 2. Multi-level regression analysis results: traditionalism-authoritarianism link across contexts

\begin{tabular}{llll}
\hline & $(1)$ & $(2)$ & $(3)$ \\
VARIABLES & $\mathrm{H} 1$ & $\mathrm{H} 2$ & $\mathrm{H} 3$ and H4 \\
\hline \multirow{2}{*}{ Contextual traditionalism } & & & \\
& & & $\mathbf{- 0 . 0 4 6 * * *}$ \\
Contextual religiosity & & $\mathbf{- 0 . 0 1 2 *}$ & $0.009)$ \\
& & $(0.007)$ & $(0.010)$ \\
Time (wave) & $\mathbf{0 . 0 1 4 * *}$ & $\mathbf{0 . 0 1 1} *$ & -0.011 \\
& $(0.006)$ & $(0.006)$ & $(0.010)$ \\
Contextual authoritarianism & 0.000 & 0.018 & $0.040^{* * v i i}$ \\
& $(0.018)$ & $(0.021)$ & $(0.022)$ \\
Constant & $0.122^{* * *}$ & $0.150^{* * *}$ & $0.319^{* * *}$ \\
& $(0.044)$ & $(0.045)$ & $(0.073)$ \\
Random Effects (variance): & & & \\
Country & 0.0017 & 0.0015 & 0.0014 \\
& $(0.0010)$ & $(0.0009)$ & $(0.0008)$ \\
Country-year & 0.0027 & 0.0026 & 0.0023 \\
& $(0.0006)$ & $(0.0006)$ & $(0.0005)$ \\
Number of contexts & 64 & 64 & 64 \\
Number of countries & 17 & 17 & 17 \\
$\mathrm{R}^{2}$ (Bryk/Raudenbush) & 0.09 & 0.10 & 0.25 \\
\hline
\end{tabular}

Standard errors in parentheses; unstandardized coefficients reported. $* * * \mathrm{p}<0.01, * * \mathrm{p}<0.05, * \mathrm{p}<0.1$ 


\section{Appendix}

8.1. Effective sample size for contexts in waves

\begin{tabular}{llllll} 
No & Country & $\mathbf{1 9 8 1}$ & $\mathbf{1 9 9 0}$ & $\mathbf{1 9 9 9}$ & $\mathbf{2 0 0 8}$ \\
\hline 1 & Austria & $N A$ & 1460 & 1522 & 1417 \\
2 & Belgium & 1145 & 2792 & 1912 & 1501 \\
3 & Denmark & 1182 & 1030 & 1018 & 1264 \\
4 & Finland & $N A$ & 588 & 1038 & 1088 \\
5 & France & 1200 & 1002 & 1615 & 1480 \\
6 & Germany & 1305 & 3437 & 1815 & 1879 \\
7 & Iceland & 927 & 702 & 965 & 756 \\
8 & Ireland & 1217 & 1000 & 1004 & 775 \\
9 & Italy & 1348 & 2018 & 2000 & 1373 \\
10 & Malta & 467 & 393 & 1002 & 1394 \\
11 & Netherlands & 1221 & 1017 & 1003 & 1447 \\
12 & Norway & 1051 & 1239 & $N A$ & 1081 \\
13 & Portugal & $N A$ & 1185 & 1000 & 1490 \\
14 & Spain & 2303 & 2637 & 1200 & 1461 \\
15 & Sweden & 954 & 1047 & 1015 & 1187 \\
16 & UK & 1167 & 1484 & 1000 & 1500 \\
17 & Northern Ireland & 312 & 304 & 1000 & 403 \\
\hline
\end{tabular}

\subsection{Descriptive statistics for all variables in use}

\begin{tabular}{llllll}
\hline Variable & $\mathrm{N}$ & Mean & Std. Dev. & Min & Max \\
\hline Individual-level & & & & & \\
$\begin{array}{l}\text { Moral traditionalism } \\
\text { Secular authoritarianism }\end{array}$ & 69,175 & 6.12 & 2.62 & 0 & 10 \\
Religiosity & 69,175 & 2.3 & 1.87 & 0 & 10 \\
\hline Contextual level & & & & & \\
Traditionalism- & 64 & 0.16 & 0.07 & 0.01 & 0.29 \\
$\begin{array}{l}\text { authoritarianism } \\
\text { correlation }\end{array}$ & & & & & \\
$\begin{array}{l}\text { Contextual moral } \\
\text { traditionalism }\end{array}$ & 64 & 6.19 & 1.38 & 3.27 & 9.61 \\
$\begin{array}{l}\text { Contextual religiosity } \\
\text { Contextual secular }\end{array}$ & 64 & 5.13 & 1.95 & 2.33 & 9.28 \\
authoritarianism & 64 & 2.31 & 0.51 & 1.32 & 4.01 \\
\hline $\begin{array}{l}\text { Moral traditionalism } \\
\text { items }\end{array}$ & & & & & \\
Homosexuality justifiable & 66,453 & 6.23 & 3.44 & 1 & 10 \\
$\begin{array}{l}\text { Abortion justifiable } \\
\text { Suicide justifiable }\end{array}$ & 67,994 & 6.45 & 3.05 & 1 & 10 \\
$\begin{array}{l}\text { Divorce justifiable } \\
\text { Euthanasia justifiable }\end{array}$ & 68,934 & 8.13 & 2.53 & 1 & 10 \\
& 67,993 & 6.42 & 2.97 & 1 & 10 \\
& & & 3.19 & 1 & 10
\end{tabular}




\begin{tabular}{|c|c|c|c|c|c|}
\hline \multicolumn{6}{|l|}{$\begin{array}{l}\text { Secular authoritarianism } \\
\text { items }\end{array}$} \\
\hline Immigrants as neighbors & 69,051 & 0.11 & 0.32 & 0 & 1 \\
\hline $\begin{array}{l}\text { People of different race as } \\
\text { neighbors }\end{array}$ & 69,060 & 0.09 & 0.29 & 0 & 1 \\
\hline Muslims as neighbors & 55,339 & 0.17 & 0.37 & 0 & 1 \\
\hline Ex-criminals as neighbors & 68,971 & 0.36 & 0.48 & 0 & 1 \\
\hline Jobs scarcity vs migrants & 54,266 & 2.27 & 0.92 & 1 & 3 \\
\hline \multicolumn{6}{|l|}{ Religiosity items } \\
\hline Believe in God & 65,635 & 0.75 & 0.43 & 0 & 1 \\
\hline Believe in life after death & 62,460 & 0.54 & 0.5 & 0 & 1 \\
\hline Believe in hell & 66,271 & 0.28 & 0.45 & 0 & 1 \\
\hline Believe in heaven & 66,220 & 0.47 & 0.5 & 0 & 1 \\
\hline Believe in sin & 66,535 & 0.56 & 0.5 & 0 & 1 \\
\hline $\begin{array}{l}\text { Attending church at least } \\
\text { monthly }\end{array}$ & 68,946 & 0.34 & 0.47 & 0 & 1 \\
\hline
\end{tabular}

i The UK and Northern Ireland are treated separately because cultural contexts there differ dramatically, e.g. abortions are not legal in Northern Ireland, unlike the rest of the UK.

ii Moral Traditionalism-Progressiveness items: "Please tell me for each of the following statements whether you think it can always be justified, never be justified, or something in between": 1) Homosexuality; 2) Abortion; 3) Divorce; 4) Euthanasia (terminating the life of the incurably sick); 5) Suicide. All scales range from 1 (never justified) to 10 (always justifiable).

${ }^{\text {iii }}$ For separate contexts in our sample, Cronbach's alpha for the moral traditionalism scale exceeds 0.8 in $42 \%$ of cases, falls within the range of $0.7-0.8$ in $48 \%$ of cases, and is below 0.7 in only 6 cases. Malta in 1981 shows the least reliable moral traditionalism scale with Cronbach's alpha of 0.61 which is still fairly high.

iv Secular Authoritarianism-Libertarianism items: "On this list are various groups of people, could you please sort out any that you would not like to have as neighbors?" (Scale: 
binary): 1) People of a different race; 2) Immigrants/foreign workers; 3) Muslims; 4) People with a criminal record; 5) When jobs are scarce, employers should give priority to [NATIONALITY] people over immigrants (agree - neither agree nor disagree - disagree).

${ }^{v}$ The secular authoritarianism scale is undoubtedly reliable in 55 contexts out of 64 with 9 contexts showing Cronbach's alpha between 0.3 and 0.5 . The lowest score is observed for Ireland in 1981 - only 0.35 .

${ }^{\text {vi }}$ Religiosity items: 1) "Apart from weddings, funerals and christenings, about how often do you attend religious services these days?" (Options: More than once a week - Once a week - Once a month - Christmas/Easter day - Other specific holy days - Once a year - Less often - Never, practically never. The answer was coded as 1 if a respondent attends services at least once a month, and as 0 for all less frequent options); "Which, if any, of the following do you believe in?” (binary scale) 2) God; 3) Life after death; 4) Hell; 5) Heaven; 6) Sin.

vii Although it might seem that the effect of contextual authoritarianism is similar in size but opposite in direction to the one of contextual moral traditionalism in the same model, the variation in contextual authoritarianism is way lower than fore moral traditionalism and the effect is, thus, considerably smaller. The scale of contextual authoritarianism ranges from 1.32 to 4.01 while the scale for contextual moral traditionalism goes from 3.27 to 9.61 . 